Intro

\title{
Editorial: Special Issue on Disco Elysium
}

\section{$\$$ sciendo}

TOM APPERLEY, Tampere University, Finland; email: t.apperley@tuni.fi ANNA OZIMEK, University of York, UK; email: anna.ozimek@york.ac.uk 
Disco Elysium is a highly praised game that is widely recognized for its innovation and quality. In December 2019, writing for Time magazine, Matthew Gault named Disco Elysium one of the ten most important games of the decade (2010-2019) alongside the likes of Fortnite (Epic Games 2017-), Minecraft (Mojang 2011), and Pokémon GO (2016). Gault (2019) characterizes the decade as one in which "artists broke free of the business side and produced works of astounding beauty on par with any prestige television show." Disco Elysium is included on his list as "proof" that "all video games are art" (ibid.). While critical and commercial success, as well as the invocation of "art," are not themselves crucial reasons for scholars to explore a particular digital game, in the case of Disco Elysium there are many other ways that it is significant.

Each of the contributions to this special issue of the Baltic Screen Media Review on Disco Elysium highlight a different way that the game can be considered noteworthy. Anna Ozimek begins the exploration of the production context of Disco Elysium. She uses empirical data gathered from interviews with Estonian game developers to discuss the local context of game development and the impact of Disco Elysium's success on the local game development scene. This article contributes to the growing research areas of local games history exemplified by the work of Jaroslav Švelch (2018) and Melanie Swalwell (2021) - and game production studies (Kerr 2017; Sotamaa, Jan Švelch 2021).

In "Selling Elysium: The Political Economy of Radical Game Distribution," Alex Gekker and Daniel Joseph also use empirical data. This time from comments on the Steam page for the "Working Class Update" version of Disco Elysium, published in May 2020. The authors explore the class positioning of Disco Elysium, and its significance for imagining new possibilities, horizons, and potential limits for making and distributing games.

Julian Novitz examines Disco Elysium through the lens of the gothic fiction genre. Building on previous work that explores how the gothic genre features in digital games in terms of visual and environmental design (Krzywinska 2015; Kirkland 2013; Perron 2018), he argues that the gothic genre asserts itself in Disco Elysium through the constant and disorienting intrusions of the past into the present through the activation of memories. This disrupts the rationality of the policeprocedure dimension of the game, while also offering the possibility of redemption through the disorientations created by memories. These memories offer the player-character Harrier "Harry" DuBois both the chance of redemption and reconciliation between Revachol's - the city in which the game is set - troubled factions.

In "The Hanged Rhizome on the Tree: Arborescence and Multiplicity in Digital Games," Juan F. Belmonte examines the topic of multiplicity in Disco Elysium through Deleuze and Guattari's (1980) notion of the rhizome. The article explores spatial and temporal multiplicities in Disco Elysium drawing on the work of Ciara Cremin (2016) and Souvik Mukherjee (2017) to explicate how 'the rhizome' can offer ways of understanding the significance of multiplicity in digital games.

Michal Klosiński approaches Disco Elysium from the perspective of ObjectOriented Ontology (Bogost 2012; Harmann 2017) and Paul Ricoeur's (1969) existential hermeneutics. His article, "The Object that Gives Rise to Thought: Hermeneutics of Objects in Disco Elysium," uses these perspectives to explore how the unusual dialogic functions of objects in the game establish both, the inner world of Harry's troubled mind and the outer world of Disco Elysium.

Conor Mckeown offers a reading of Disco Elysium through the notion of the posthuman. In "What Kind of Cop Are You?": Disco Elysium's Technologies of Self within the Posthuman Multiverse," they contrast the approaches towards 'the posthuman' taken by N. Katherine Hayles (1999) and Karen Barad (2007) to offer a reading of Disco Elysium's avatar skill system. This highlights the centrality of the experience 
of multiple potentials and possibilities in the play of Disco Elysium which McKeown argues evokes the notion of "multiverse posthumanism."

In "'Making Sense in a Senseless World': Disco Elysium's Absurd Hero," Thomas Spies uses Albert Camus' (2005/ 1942) notion of the Absurd to examine the representations of mental health in the game. He argues that Disco Elysium presents the player with an avatar-character who is dealing with deep psychological trauma that is inextricable from the collective trauma of Revachol. But the process of playing the game, while linking individual and collective trauma, also offers ways of dealing with, confronting, and processing trauma which, Spies argues, illustrates how Disco Elysium depicts mental-health issues in a de-stigmatizing way.

Daniel Vella and Magdalena Cielecka use Mikhail Bakhtin's (1984/1963) concept of polyphony to explore the fracturing of the 'ludic self' (Vella 2016). In "You Won't Even Know Who You Are Anymore': Bakthinian Polyphony and the Challenge to the Ludic Subject in Disco Elysium" they argue that Disco Elysium demonstrates the possibility of multiple ludic subjectivities, which inverts the usual depictions of the player character, avatar, or protagonist of digital games as a discrete, autonomous figure. Vella and Cielecka suggest that, in this regard, Disco Elysium questions the assumptions and biases of the notion of subjectivity itself.

Together, the articles in this special issue of the Baltic Screen Media Review illustrate the significance of Disco Elysium to the local and global game industry, and how it advances the aesthetic and philosophical understanding of digital games. The issue demonstrates a selection of the many disciplinary perspectives and intellectual traditions which are brought to bear in interdisciplinary game studies. The collected articles affirm that digital games are multifaceted objects of study that benefit from multi-, inter-, and trans-disciplinary approaches as much as they do from focused discipline-specific inquiry.

\section{FUNDING}

Thomas Apperley's work on this special issue was funded by the Academy of Finland's Centre of Excellence in Game Culture Studies (CoE-GameCult, 312395).

\section{ACKNOWLEDGEMENTS}

This special issue of Baltic Screen Media Review relied greatly on the efforts of the peer-reviewers of the articles and the staff of the journal; both groups deserve our deep gratitude for their work which made this issue possible. Thanks also to Teet Teinemaa and Katrin Tiidenberg.

\section{REFERENCES}

Bakhtin, Mikhail 1984/1963. Problems of Dostoevsky's Poetics. Minneapolis: University of Minnesota Press. Barad, K. M. 2007. Meeting the Universe Halfway: Quantum Physics and the Entanglement of Matter and Meaning. Durham: Duke University Press.

Bogost, Ian 2012. Alien Phenomenology, or What It's Like to Be a Thing. University of Minnesota Press:

Minneapolis.

Camus, Albert 2005/1942. Myth of Sisyphus. London:

Penguin UK.

Cremin, Ciara 2016. Exploring Videogames with Deleuze and Guattari. Towards an Affective Theory of Form. London: Routledge.

Deleuze, Gilles; Guattari, Felix 2009/1980. A Thousand Plateaus. Capitalism and Schizophrenia. Minneapolis: University of Minnesota Press.

Gault, Matthew 2019 (December 19). The 10 Best Video Games of the 2010s. Time. https://time.com/5752663/ best-video-games-2010s-decade/

Harman, Graham 2017. Object-Oriented Ontology:

A New Theory of Everything. Pelican.

Hayles, N. Katherine 1999. How we Became Posthuman: Virtual Bodies in Cybernetics, Literature, and Informatics. Chicago: University of Chicago Press.

Kerr, Aphra 2017. Global Games: Production, Circulation and Policy in the Networked Era. New York: Routledge. Kirkland, Ewan 2013. 'Gothic Video games, Survival Horror and the Silent Hill Series.' - Gothic Studies 14, 2, 108-122.

Krzywinska, Tanya 2015. 'Gamification of Gothic'. Mathias Fuchs (ed.), Diversity of Play. Lüneburg: Meson Press, 21-38.

Mukherjee, Souvik 2017. 'Re-membering and dismembering: memory and the (re) creation of identities in videogames.' - Sessões do Imaginário 22, 38, 53-63. Perron, Bernard 2018. The World of Scary Videogames: A Study in Videoludic Horror. London: Bloomsbury Academic.

Ricoeur, Paul 1969. The Symbolism of Evil. Trans. Emerson Buchman. Boston: Beacon Press.

Sotamaa, Olli; Švelch, Jan (eds.). 2021. Game Production Studies. Amsterdam: Amsterdam University Press. Švelch, Jaroslav 2018. Gaming the Iron Curtain: How Teenagers and Amateurs in Communist Czechoslovakia Claimed the Medium of Computer Games. Cambridge: MIT Press.

Swalwell, Melanie 2021. Homebrew Gaming and the Beginnings of Vernacular Digitality. Cambridge: MIT Press.

Vella, Daniel 2016 “"Who am 'l' in the Game?”: A Typology of the Modes of Ludic Subjectivity'. In DiGRA/FDG'16 Proceedings of the First International Joint Conference of DiGRA and FDG. http://www.digra.org/digital-library/ publications/who-am-i-in-the-game-a-typology-ofthe-modes-of-ludic-subjectivity/ 